\title{
The Effects of $\alpha 2$-Adrenergic Receptor Agonist Dexmedetomidine on Hemodynamic Response in Direct Laryngoscopy
}

\author{
Berrin Işik, Mustafa Arslan* ${ }^{*}$ Özgür Özsoylar and Mehmet Akçabay
}

Gazi University Faculty of Medicine Department of Anesthesiology and Reanimation Besevler, Ankara, Turkey

\begin{abstract}
Background: In anesthesia practices, the prevention of sympathetic discharge is important. Dexmedetomidine is a sedative with anxiolytic and analgesic effects. However, its effects on hemodynamic response in direct laryngoscopy are not clear.

Objectives: This study aimed to compare the effects of dexmedetomidine with well-known premedication agent midazolam.

Methods: Intramuscular $0.05 \mathrm{mgkg}^{-1}$ midazolam (GroupM) or intravenous $1 \mu \mathrm{gkg}^{-1}$ dexmedetomidine (GroupD) was applied to cases who were scheduled for direct laryngoscopy under general anesthesia. Heart Rate and mean arterial pressure (MAP) were measured before premedication and noted down as control values. Preoperative hemodynamic parameters, recovery times and sedation levels of both groups were compared.

Results: In the comparison of MAP of the groups at the postintubation $1^{\text {st }}$ and $5^{\text {th }}$ min, the values of Group M were significantly higher $(\mathrm{p}=0.04, \mathrm{p}=0.002)$. Mean postintubation MAP values at the $1^{\mathrm{st}}, 5^{\text {th }}$, and $10^{\text {th }}$ min and mean postextubation MAP values, at the $1^{\text {st }}$ min of GroupM were significantly higher than the mean control MAP $(\mathrm{p}=0.001, \mathrm{p}=0.003, \mathrm{p}=0.008$, $\mathrm{p}=0.002, \mathrm{p}=0.008$ respectively).

Conclusion: Dexmedetomidine premedication is a more effective alternative to midazolam premedication for hemodynamic stabilization and early recovery in direct laryngoscopy operation.
\end{abstract}

Keywords: Laryngoscopy, dexmedetomidine, midazolam, recovery.

\section{INTRODUCTION}

The stress caused by surgery and anesthesia leads to an endocrine response starting adrenalin and noradrenalin secretion by the stimulation of sympathetic nervous system [1]. The elevated catecholamine concentration in plasma due to sympathetic discharge increases the arterial blood pressure (BP), heart rate (HR) and oxygen consumption, leading to hemodynamic instability [2,3]. Direct laryngoscopy interventions involve severe sympathetic stimulation. Modern anesthesia practices aim to prevent sympathetic discharge and provide hemodynamic stability. To this end, in addition to general anesthesia, various agents such as opioids, local anesthetics, adrenergic blockers, Ca-canal blockers and nitroglycerine have been used [4-6].

Sedative drugs control anxiety besides reducing the sympathetic discharge. Controlling anxiety provides comfort to the patient. This characteristic of sedative premedication agent is their desired property.

Midazolam is the most commonly used sedative in adults. It provides potent sedation, loss of memory and anxiolysis and is preferred over the longer-acting benzodiazepines $[7,8]$.

Dexmedetomidine is a selective $\alpha 2$-adrenergic receptor agonist and presents dose-dependent decreased HR and BP, sedative anxiolytic and analgesic effects $[5,9,10]$.

\footnotetext{
*Address correspondence to this author at 48. Sokak, Seda Apartmanı, 24/17, Yenimahalle, Kirikkale, Turkey; Tel: 9031821205 26; Fax: 90318 21600 00; E-mail: marslan36@yahoo.com, marslan36@hotmail.com
}

In direct larygoscopi operation presenting excessive sympathetic stimulation, restriction of sympathetic response, obtaining adequate sedation and early recovery, not contributing to manifestation of respiratory depression, are very important.

This clinical study aimed to compare the effect on peroperative hemodynamic stability and sedation with intravenous (IV) dexmedetomidine premedication versus intramuscular (IM) midazolam premedication in direct laryngoscopy.

\section{PATIENTS AND METHODS}

\section{Subjects}

This prospective, randomized, double-blinded study involved 40 patients and was conducted under ethics' committee permission. American Society of Anesthesiologists (ASA) I-III group male and female patients of 18-55 years of age scheduled for direct laryngoscopy under general anesthesia by Otolaryngology Head and Neck Surgery Department of the Faculty of Medicine, Gazi University, Turkey were selected for the study on voluntary basis. In this research, the patients who, for whatever reason indicated direct laryngoscopy, were involved. The exclusion criteria were established as neck dissection planned for post direct laryngoscopy, a procedural time of over one hour, the presence of heart deficiency and hypertension, regular drug use, or a history of known allergy and intraoperative inadequate depth of anesthesia. All the cases were evaluated according to Ramsay Sedation Scale (RSS) and sedation levels (Table 1). 
Table 1. Ramsay Sedation Scale

\begin{tabular}{|l|c|}
\hline \multicolumn{1}{|c|}{ Sedation Level } & Score \\
\hline \hline Patient is anxious and agitated or restless, or both & 1 \\
\hline Patient is co-operative, oriented, and tranquil & 2 \\
\hline Patient responds to commands only & 3 \\
\hline $\begin{array}{l}\text { Patient exhibits brisk response to light glabellar tap or loud } \\
\text { auditory stimulus }\end{array}$ & 4 \\
\hline $\begin{array}{l}\text { Patient exhibits a sluggish response to light glabellar tap or } \\
\text { loud auditory stimulus }\end{array}$ & 5 \\
\hline Patient exhibits no response & 6 \\
\hline
\end{tabular}

\section{Anesthetic Management}

All patients HR and mean arterial pressure (MAP) were measured in the operating room and noted down as a control value (Drager PM 8060 Vitara Type:8601578 Serial Nr: ARSC-0006 Made in Germany, Drager-edizinetechnik GmbH 0-23542-Lübeck ${ }^{\circledR}$ ). The patients were randomly divided into two groups, and one group (Group $\mathrm{M}$ ) received im $0.05 \mathrm{mg} \mathrm{kg}^{-1}$ midazolam (Dormicum ${ }^{\circledR}$ ) $30 \mathrm{~min}$ before anaesthesia induction. The patients in both groups were moved onto the operation table 10 min before induction. Heart rate by electrography, peripheral oxygen saturation $\left(\mathrm{SpO}_{2}\right)$ with pulse oxymeter and systolic, diastolic and MAP by noninvasive methods were measured. After measuring the vital signs by monitor, the other group (Group D) received IV $1 \mu \mathrm{g} \mathrm{kg}^{-1}$ dexmedetomidine (Precedex ${ }^{\mathbb{B}}$ ) in $20 \mathrm{~mL}$ serum saline set up to be infused in 10 minutes.

The patients in both groups were followed for any undesired or unexpected side effect after premedication administration until the postoperative $4^{\text {th }}$ hour. A researcher blinded to the groups of the patients performed both the anesthesia application and follow-up of the patients; thus, rendering the study blinded. Just before the anesthesia induction, the sedation levels were re-evaluated by RSS. The anesthesia procedure was standardized. Induction was achieved with $2 \mathrm{mg}$ $\mathrm{kg}^{-1}$ propofol (Propofol 1\% Fresenius Kabi Istanbul Tur$\mathrm{key}^{\circledR}$ ) and muscle relaxation was achieved with $1 \mathrm{mg} \mathrm{kg}^{-1}$ succinylcholine (Lystenon $5 \mathrm{~mL} 100 \mathrm{mg}$ forte ampul Fako Ilaç Istanbul Turkey ${ }^{\circledR}$ ). After sufficient muscle relaxation, orotracheal intubation was realized with the use of a tube being 2-3 degrees smaller than the proper size and laryngoscopy was performed.

Anesthesia was maintained by $50 / 50 \% \mathrm{O}_{2} / \mathrm{N}_{2} \mathrm{O}$ with 1.5 $2 \%$ sevoflurane end tidal concentration, and the tidal volume was set approximately for $10 \mathrm{~mL} \mathrm{~kg}{ }^{-1}$ at 8-14 frequency (Drager-Julian Plus Drager-Medical, A Drager and Siemens Company). We planned to apply single dose $\left(0.5 \mathrm{mg} \mathrm{kg}^{-1}\right)$ of atracurium besylate (Tracrium $50 \mathrm{mg} / 5 \mathrm{~mL}$ GlaxoSmith Kline $U^{\circledR}{ }^{\circledR}$ ) when patients' spontaneous respiratory effort was observed. A 3-5 mL kg ${ }^{-1} \mathrm{hr}^{-1}$ Ringer Lactate infusion was attained peroperatively through peripheral vein. A heart rate less than 60 beats per minute was considered bradycardia and less than 45 beats per minute, severe bradycardia. A blood pressure of $25 \%$ less than the control values was considered hypotension and $25 \%$ more than the control values was considered hypertension. In case of severe bradycardia,
$1 \mathrm{mg}$ atropine and in case of hypotension, when increasing crystalloid rate was not sufficient, $0.1 \mathrm{mg} \mathrm{kg}{ }^{-1}$ ephedrine administrations were planned. Furthermore, in case of hypertension, when increasing concentration of sevoflurane to $25 \%$ was not sufficient $1 \mu \mathrm{g} \mathrm{kg}^{-1} \mathrm{~min}^{-1} 1,2,3$-trinitrooxypropane (Perlinganit) infusion was planned. Patients had tachycardia and hypertension in addition to at least signs of lacrimation, pupiller dilatationand arrhythmia and attempted movement during operation was concludedas being due to insufficient depth of anesthesia. In this research, we planned the exclusion of those patients presenting with insufficient depth of anesthesia excluded from the study. All the laryngoscopy procedures were performed by the same team of five surgeons. At the end of the procedure, inhalation agent was ended and initially, $100 \% \mathrm{O}_{2}$ followed $50 / 50 \% \mathrm{O}_{2} /$ air were pumped for breathing. When the patients' tidal volume was $\geq 8 \mathrm{~mL} \mathrm{~kg}$, respiration was deduced to be regular and $\mathrm{SpO}_{2} \geq$ 98 extubation was performed.

Extubation time was determined as the time of closing the sevoflurane and extubation interval. The spontaneous eye opening, eye opening to verbal stimulus, person, place and time orientation times were considered to assess recovery.

At the $1^{\text {st }}, 5^{\text {th }}, 10^{\text {th }}, 15^{\text {th }}, 30^{\text {th }}, 60^{\text {th }}$, and $240^{\text {th }}$ min after extubation, MAP, HR, and sedation levels based on RSS were evaluated. The operation and anesthesia times of the patients who were monitored in the postoperative recovery room for at least one hour were recorded and when their vital findings were stable and general conditions were good, they were transferred to their services where their follow-up continued. All the patients were questioned for awareness at the postoperative $4^{\text {th }}$ hours and noted down.

The demographic data, pre and postoperative HR, MAP, sedation levels based on RSS, side effects, and postoperative recovery times were compared.

\section{Statistical Analysis}

Statistical evaluation was performed in SPSS for Windows, Version 11 software through the tests mentioned below and $\mathrm{p}<0.05$ was considered significant. The results were expressed as [mean $\pm \mathrm{SD}$, median $(25 \%-75 \%), \mathrm{n}(\%)]$.

Student's $t$ test was used for within group comparisons of age, weight, height, surgery, anesthesia, extubation and recovery times. Repeated measures of variance analysis evaluated MAP and HR. Bonferroni adjustment was used in the comparisons of within group values of mean MAP and HR, in which the time factor was identified as important through repeated measures of variance analysis. Mann-Whitney-U test was used in simultaneous comparison of RSS data of the groups. Chi-square and Fisher's exact test compared gender, ASA, number of the cases with given atracurium besylate, pre, intra and postoperative side effects of the groups.

\section{RESULTS}

All of the 40 patients enrolled into the study were evaluated. The age, weight, height and gender characteristics and American Society of Anesthesiologists (ASA) risk group, anesthesia, surgery and intubation's time of the groups were similar (Table 2). Number of the cases who were given atracurium besylate of the groups was similar (Table 2). No patient informed us about peroperative awareness. 
Table 2. Demographic Characteristics and Procedure Times $[\mathrm{Mean} \pm \mathrm{SD}, \mathrm{n}(\%)]$

\begin{tabular}{|l|c|c|c|}
\hline & Group D (n=20) & Group M (n=20) & $\mathbf{p}$ \\
\hline \hline Age (yr) & $46.7 \pm 11.2$ & $50.9 \pm 9.6$ & 0.889 \\
\hline Weight (kg) & $75.4 \pm 12.3$ & $73.3 \pm 15.6$ & 0.959 \\
\hline Height (cm) & $165.2 \pm 6.6$ & $166.5 \pm 8.2$ & 0.889 \\
\hline ASA (I/II/III) & $8 / 8 / 4$ & $6 / 9 / 5$ & 0.545 \\
\hline Gender (W/M) & $14 / 6$ & $12 / 8$ & 0.206 \\
\hline Anesthesia time (min) & $32.3 \pm 8.2$ & $34.9 \pm 10.5$ & 0.177 \\
\hline Surgical time (min) & $24.8 \pm 8.1$ & $26.6 \pm 10.3$ & 0.207 \\
\hline Atracurium besilate & $11(55)$ & $15(75)$ & 0.320 \\
\hline
\end{tabular}

The MAP at various times has been presented in Fig. (1). In the comparison of MAP of the groups at the postintubation $1^{\text {st }}$ and $5^{\text {th }}$ min, the values of Group $M$ were significantly higher $(\mathrm{p}=0.04, \mathrm{p}=0.002)$. Time-dependent intragroup differences compared to the control values were as follows: Mean postintubation MAP of Group M at the $1^{\text {st }}, 5^{\text {th }}$, and $10^{\text {th }}$ min were significantly higher than the mean control MAP $(\mathrm{p}=0.001, \mathrm{p}=0.003, \mathrm{p}=0.008$, respectively). However, Group D had no differences compared to the control value ( $\mathrm{p}$ $>0.05)$. In the comparison of mean postextubation MAP values, the $1^{\text {st }}$ and $5^{\text {th }}$ min values of Group $M$ were significantly higher than the control value $(\mathrm{p}=0.002, \mathrm{p}=0.008)$ (Fig. 1).

The mean values of HR at various measurement times have been provided in Fig. (2). Upon the comparison of HR means of groups for differences in time, although the mean HR values of Group $M$ for all the minutes were high, only the mean postinduction HR value was significantly higher. $(p=0.024)$. Intragroup differences of the mean HR values at various times were as follows: the values of Group D did not significantly differ at any of the measurement times. The postintubation $1^{\text {st }}$ min value of Group $M$ reached at a significantly high level $(p=0.04)$. The mean postextubation HR values of both groups did not significantly differ from the mean control values (Fig. 2). Perlinganit infusion was not required for any patient in each groups.

The eye opening to verbal stimulus and spontaneous eye opening times of Group D were significantly shorter than those of Group M ( $p=0.035, p=0.019$, respectively). However, there were no significant differences between the two groups for place, time and individual orientation times $(\mathrm{p}>$ 0.05) (Fig. 3).

The sedation levels based on RSS did not show any differences before anaesthesia induction and from the 5 th minute of postextubation ( $p>0.05$ ), while mean postextubation 1st min value of Group D was lower ( $\mathrm{p}=0.045)$ (Fig. 4).

In the evaluation of side effects, 1 patient $(5 \%)$ in Group $\mathrm{D}$ and 6 patients $(30 \%)$ in Group $\mathrm{M}$ had sedation. The postoperative sedation incidence of Group $M$ was higher than that of Group D $(p=0.046)$. There were no statistically significant differences between the two groups for the values of the other side effects (Table 3 ). In one of the 4 patients with preoperative bradycardia, HR was below 45 beats $\mathrm{min}^{-1}$; thus, atropine was administered.

There were no statistically significant differences between the two groups for the values of the intraoperative side effects (Table 4).

\section{DISCUSSION}

In the interventions like direct laryngoscopy involving severe sympathetic stimuli, prevention of tachycardia, hypertension and elevated total oxygen consumption due to

$\square$ Group D MAP $\quad \square$ Group M MAP

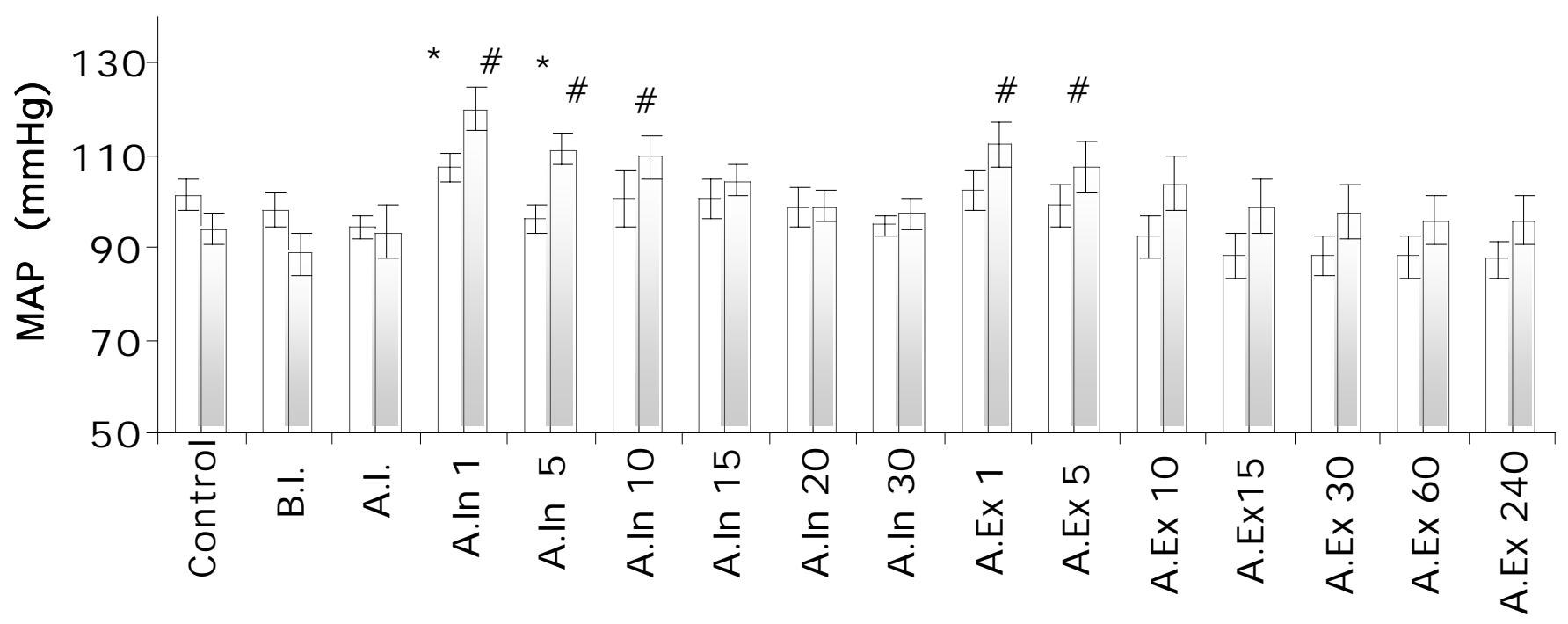

B.I.: Before induction, A.I.: After induction, A.In.: After intubation, A.Ex.: After extubation. \# $\mathrm{p}<0.05$ before control.

* $\mathrm{p}<0.05$ Compared to the values of Group D.

Fig. (1). Perioperative mean arterial pressure (MAP) values (Mean SD). 


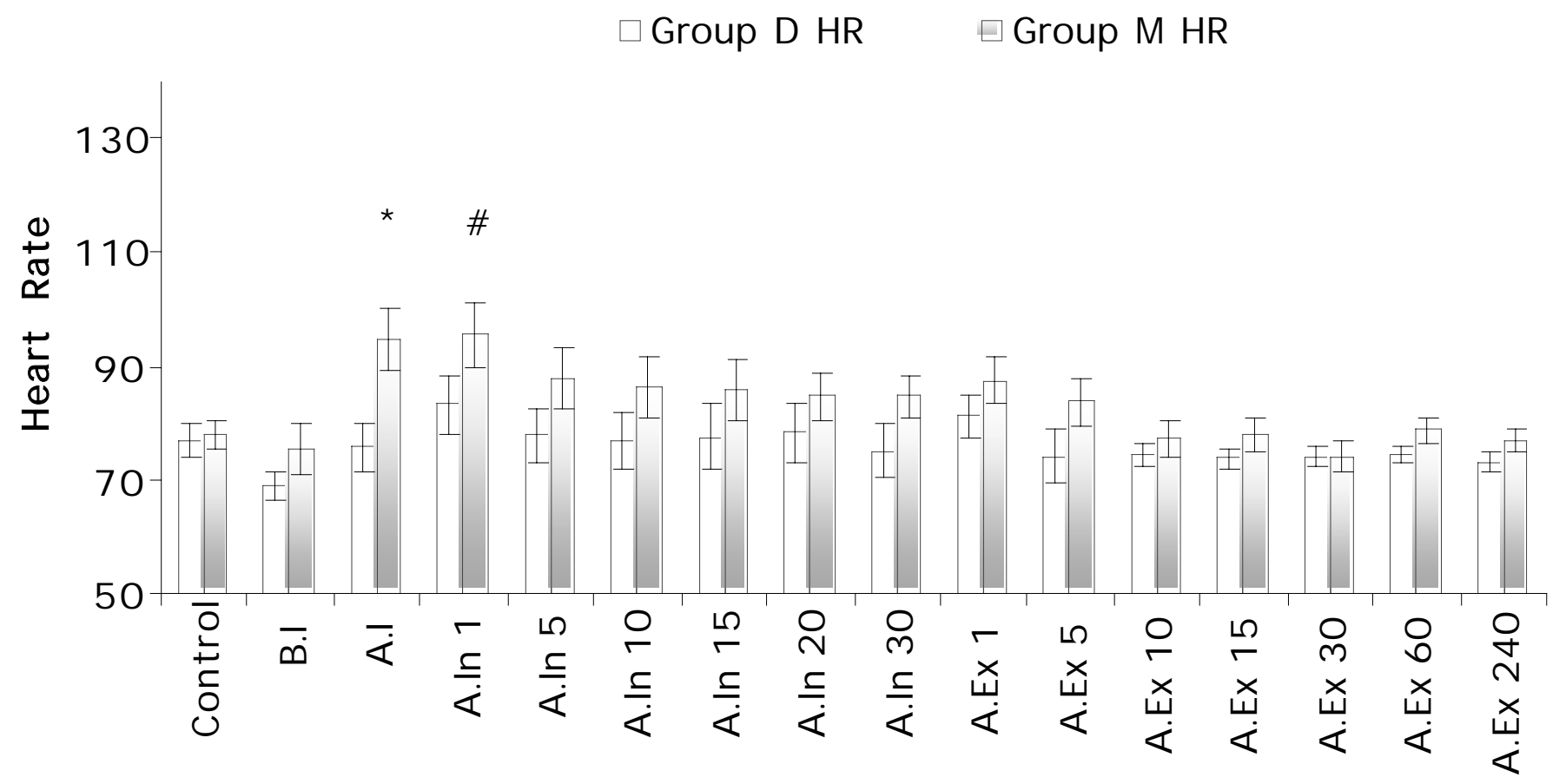

B.I.: Before induction, A.I.: After induction, A.In.: After intubation, A.Ex.: After extubation. ${ }^{\mathrm{p}} \mathrm{p}<0.05$ before control.

" $\mathrm{p}<0.05$ Compared to the values of Group D.

Fig. (2). Peroperative heart rate (HR) values (Mean SD).

$\square$ Group D $\square$ Group M

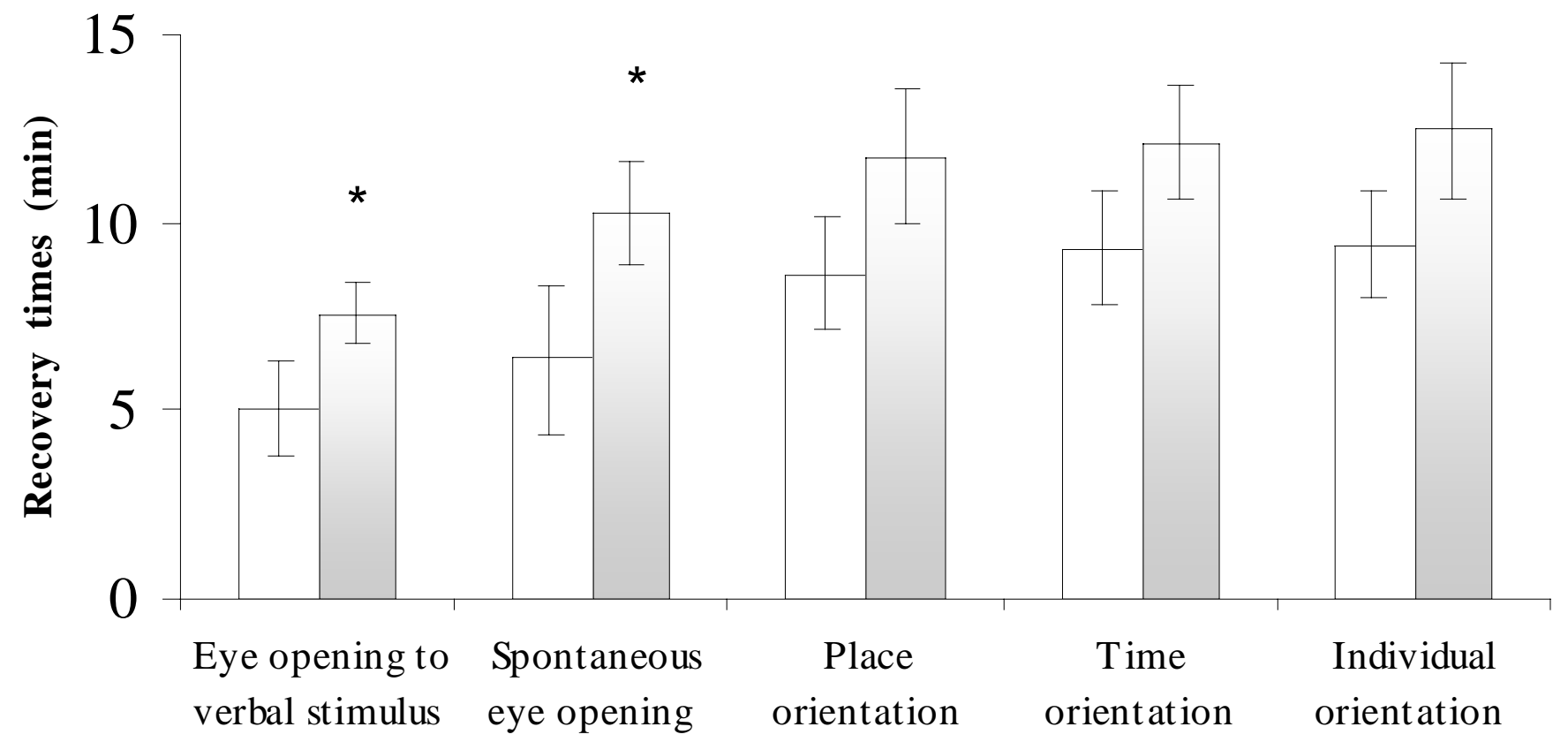

${ }^{*} \mathrm{p}<0.05$ Compared to the values of Group D.

Fig. (3). Recovery times of the groups (Mean SD).

sympathetic activity, increase may prove particularly beneficial to the patients with limited cardiac reserve [2-5,10]. Different pharmacologic agents are used for prevention of sympathetic discharge [4-6].
In various studies, dexmedetomidine, an $\alpha 2$-adrenoreceptor agonist, has been shown to decrease plasma catecholamine and to suppress cardiovascular and endocrine response through central sympathetic blockage $[8,11,12]$. 


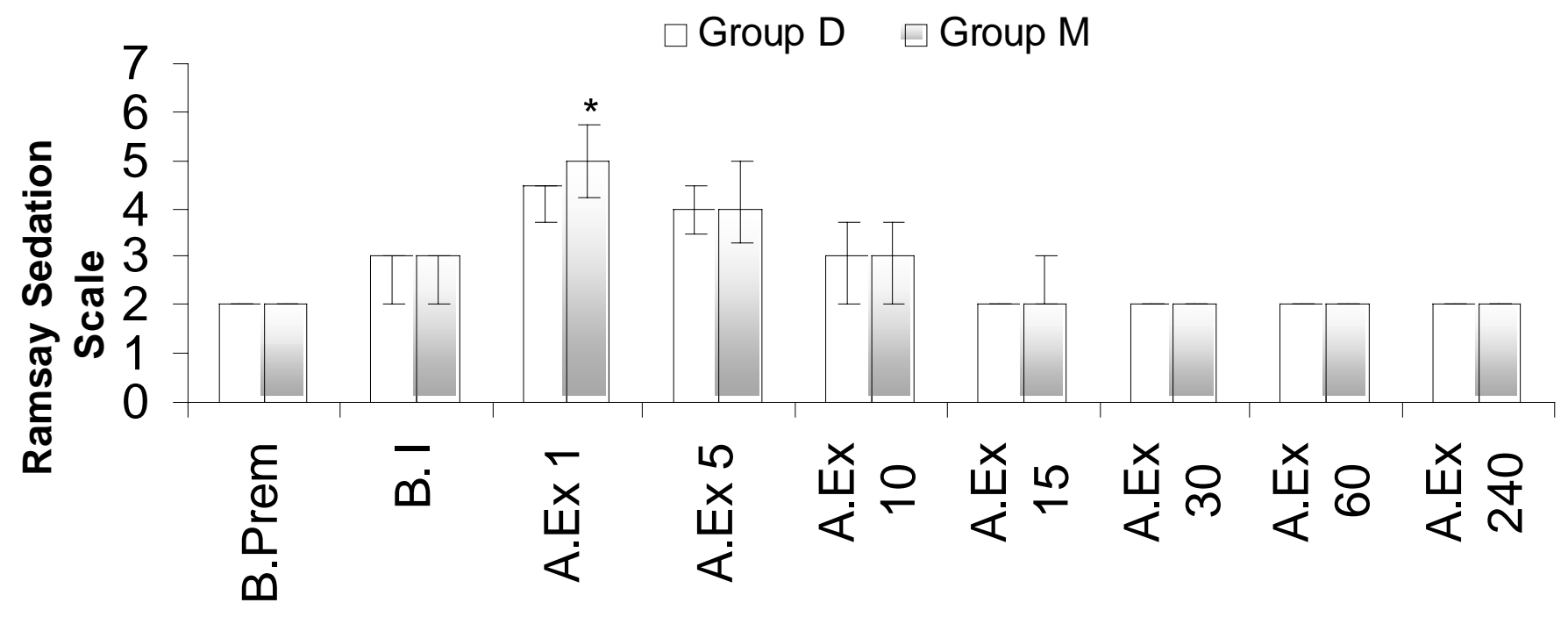

\section{Time (min)}

B.Prem.: Before premedication, B.I.: Before induction, A.Ex.: After extubation. " $\mathrm{p}<0.05$ Compared to the values of Group D.

Fig. (4). Perioperative Sedation levels (median (25\%-75\%)).

In the cases subjected to direct laryngoscopy by otolaryngology surgery, the comparison of the effects of $1 \mu \mathrm{g} \mathrm{kg}^{-1}$ IV dexmedetomidine premedication and $0.5 \mathrm{mg} \mathrm{kg}^{-1} \mathrm{IM} \mathrm{mi-}$ dazolam in two groups indicated that dexmedetomidine stabilizes BP and HR at low levels.

Table 3. Preoperative and Postoperative Side Effects (n, (\%))

\begin{tabular}{|l|c|c|c|}
\hline & $\begin{array}{c}\text { Group D } \\
(\mathbf{n = 2 0})\end{array}$ & $\begin{array}{c}\text { Group M } \\
(\mathbf{n = 2 0})\end{array}$ & $\mathbf{p}$ \\
\hline \hline Preoperative bradycardia & $4(20)$ & $0(0)$ & 0.106 \\
\hline Preoperative nausea-vomiting & $0(0)$ & $0(0)$ & \\
\hline Pain & $18(90)$ & $17(85)$ & 0.633 \\
\hline Postoperative nausea & $2(10)$ & $0(0)$ & 0.487 \\
\hline Postoperative vomiting & $0(0)$ & $0(0)$ & \\
\hline Respiratory difficulty & $3(15)$ & $2(10)$ & 0.633 \\
\hline Hypotension & $1(5)$ & $0(0)$ & 0.500 \\
\hline Hypertension & $1(5)$ & $4(20)$ & 0.342 \\
\hline Postoperative bradycardia & $1(5)$ & $1(5)$ & \\
\hline Tremor & $0(0)$ & $2(10)$ & 0.487 \\
\hline Laryngospasm & $0(0)$ & $3(15)$ & 0.231 \\
\hline Cough & $0(0)$ & $3(15)$ & 0.231 \\
\hline Sedation & $1(5)$ & $6(30)^{*}$ & 0.046 \\
\hline Agitation & $3(15)$ & $1(5)$ & 0.302 \\
\hline *p $<0.05$ Compared to the values of Group D. & & \\
\hline
\end{tabular}

Some studies have reported that a single dose of intravenous dexmedetomidine completely blocks norepinephrine (NE) secretion of sympathetic nerves and leads to a $92 \%$ decrease of plasma NE levels, through which MAP and HR
Table 4. Intraoperative Side Effects (n, (\%))

\begin{tabular}{|l|c|c|c|}
\hline & Group D (n=20) & Group M (n=20) & p \\
\hline \hline Tachycardia & $2(10)$ & $6(30)$ & 0.235 \\
\hline Hypertension & $1(5)$ & $5(25)$ & 0.182 \\
\hline Lacrimation & $1(5)$ & $2(10)$ & 0.548 \\
\hline Pupiller dilatation & $0(0)$ & $0(0)$ & \\
\hline Arythmia & $0(0)$ & $0(0)$ & \\
\hline Attemped movement & $0(0)$ & $0(0)$ & \\
\hline
\end{tabular}

are decreased; thus, no compensatory changes take place in the endocrine system $[8,13]$. Bloor et al. [14] reported that $1 \mu \mathrm{g} \mathrm{kg}^{-1}$ dexmedetomidine administration in 2 minutes renders $16 \%$ increase in MAP followed by $23 \%$ decrease. Similarly, Hall et al. [15] maintained that $1 \mu \mathrm{g} \mathrm{kg}^{-1}$ of dexmedetomidine first leads to an increase in HR and arterial blood pressure particularly in young and healthy individuals and then to a decrease following 0.2-0.7 $\mu \mathrm{g} \mathrm{kg}^{-1} \mathrm{hr}^{-1}$ dexmedetomidine infusion, however, MAP and HR are significantly lower when compared to placebo findings, and upon withdrawal of the drug, it took 6 hours to achieve the basal levels with no rebound effect [8]. In the study of Taittonen et al. [16] a single dose of im $2.5 \mu \mathrm{g} \mathrm{kg}^{-1}$ dexmedetomidine lowered HR by $18 \%$, postoperative systolic pressure by $11 \%$ and postoperative diastolic pressure by $15 \%$. Unlike the findings of other studies, they reported a tendency of MAP and HR to increase postoperatively and attributed this slightly hypertensive response to the activation of postsynaptic $\alpha 2$ adrenoreceptors causing vasoconstriction of the smooth muscles of the arteries. In our study, immediately after dexmedetomidine administration or during postoperative followup, no hypertension tendency was detected. We observed HT 
in $1(5 \%)$ patient in Group D and in $5(25 \%)$ patients in Group M.

One of the advantages of dexmedetomidine used as a premedication is relatively lower amount of anesthetic and analgesic agents used $[8,12,17]$. Dexmedetomidine has been reported to reduce sevoflurane needed by $17 \%$ of older patients [18]. Anesthetics used in induction and maintenance were standardized in our study.

Sevoflurane concentration was maintained in $1.5-2 \%$ in two groups. In case of hypertension and tachycardia, sevoflurane concentration was increased by $25 \%$. If the patients presenting with hypertension and tachycardia associated with sign of the subjective sympathetic discharge (lacrimation, pupiller dilatation, arrhythmia, attempted movement) were accepted as insufficient depth of anesthesia. No patient was excluded because of insufficient depth of anesthesia. The mean end tidal sevoflurane concentration was similar in the two groups.

Intramuscular $2.5 \mu \mathrm{g} \mathrm{kg}^{-1}$ dexmedetomidine has similar sedation effect as that of $0.08 \mathrm{mg} \mathrm{kg}^{-1}$ midazolam [19]. Literature review revealed no studies comparing the sedative effects of im $0.05 \mathrm{mg} \mathrm{kg}^{-1}$ midazolam premedication and IV $1 \mu \mathrm{g} \mathrm{kg}^{-1}$ dexmedetomidine premedication. The studies comparing dexmedetomidine with placebo have used reduced amounts of anesthetics and analgesics due to the effects of dexmedetomidine and reported shorter recovery time [20]. In this study, preoperative sedation levels of both groups evaluated through RSS were similar, whereas in Group M postoperative recovery parameters were longer and more patients $(6 / 1)$ in midazolam group had sedation for first 10 minutes after extubation period.

The evaluation of recovery times after anesthesia showed that dexmedetomidine group had shorter spontaneous eye opening and eye opening to verbal stimulus. However, individual, place, and time orientation did not differ.

The studies using dexmedetomidine have commonly reported side effects of sinus pause or bradycardia and recommended glycopyrrolate or atropine for the treatment $[8,12]$. Peden et al. [21] suggested anticholinergic prophylaxis before dexmedetomidine administration in the patients less than 40 years of age. In our study, preoperative HR of 3 patients in dexmedetomidine group was below 60 and of 1 patient, below 45. The HR of the patients was normalized after IV administration of $1 \mathrm{mg}$ atrophine.

Tremor is one of the side effects of anaesthesia in recovery time with varying incidence, reported to be as high as $70 \%$, associated with anesthetic or analgesic agents used $[22,23]$. In our study, the incidence of postoperative tremor did not statistically differ between the two groups. In Group M, 2 patients experienced tremor, while none of the patients in Group D suffered from such a side effect. Relatively lower incidence of tremor in both groups than as reported in the literature may have been associated with propofol used in the induction and covering up the patients to prevent heat loss after anesthesia.

In this research we could not use BIS monitor, which is our handicap. But subjective parameters of insufficient depth of anesthesia (Tachycardia, hypertension, lacrimation, pupiller dilatation, arrhythmia, and attempted movement) might be utilized [24]. In this research, we planned those patients with insufficient depth of anesthesia to be excluded from the study but no patient was excluded because of insufficient depth of anesthesia. No patient informed us about peroperative awareness. The mean end tidal sevoflurane concentrations were similar in the two groups.

In conclusion, although our study group was not large in number, the findings of our study showed that dexmedetomidine premedication in direct laryngoscopy procedures controls hypertension and tachycardia more efficiently without prolonged recovery time than midazolam premedication does and therefore can be safely used through a closer follow-up.

\section{REFERENCES}

[1] Udelsman R, Norton JA, Jelenich SE, et al. Responses of the hypothalamic-pituitary-adrenal and renin-angiotensin axes and the sympathetic system during controlled surgical and anesthetic stress. J Clin Endocrinol Metab 1987; 64: 986-994.

[2] Kovac AL. Controlling the hemodynamic response to laryngoscopy and endotracheal intubation. J Clin Anesth 1996; 8: 63-79.

[3] Taittonen MT, Kirvela OA, Aantaa R, et al. Effect of clonidine and dexmedetomidine premedication on perioperative oxygen consumption and haemodynamic state. Br J Anaesth 1997; 78: 400406.

[4] Mikawa K, Nishina K, Maekawa N, et al. Comparison of nicardipine, diltiazem and verapamil for controlling the cardiovascular responses to tracheal intubation. Br J Anaesth 1996; 76: 221-226.

[5] Talke P, Richardson CA, Scheinin M, et al. Postoperative pharmacokinetics and sympatholytic effects of dexmedetomidine. Anesth Analg 1997; 85:1136-1142.

[6] van den Berg AA, Halliday EM, Soomro NA, et al. Reducing cardiovascular responses to laryngoscopy and tracheal intubation: a comparison of equipotent doses of tramadol, nalbuphine and pethidine, with placebo. Middle East J Anesthesiol 2004; 17:10231036.

[7] Dundee JW, Halliday NJ, Harper KW, et al. Midazolam. A review of its pharmacological properties and therapeutic use. Drugs 1984; 28: 519-543.

[8] Bhana N, Goa KL, McClellan KJ. Dexmedetomidine. Drugs 2000; 59: 263-270.

[9] Bekker AY, Kaufman B, Samir H, et al. The use of dexmedetomidine infusion for awake craniotomy. Anesth Analg 2001; 92:1251-1253.

[10] Kihara S, Brimacombe J, Yaguchi Y, et al. Hemodynamic responses among three tracheal intubation device in normotensive and hypertensive patients. Anesth Analg 2003; 96: 890-895.

[11] Talke P, Chen R, Thomas B, et al. Hemodynamic and adrenergic effects of perioperative dexmedetomidine infusion after vascular surgery. Anesth Analg 2000; 90: 834-839.

[12] Coursin DB, Coursin DB, Maccioli GA. Dexmedetomidine. Curr Opin Crit Care 2001; 7: 221-226.

[13] Kallio A, Scheinin M, Koulu M, et al. Effects of dexmedetomidine, a selective alpha 2-adrenoceptor agonist, on hemodynamic control mechanisms. Clin Pharmacol Ther 1989; 46: 33-42.

[14] Bloor BC, Ward DS, Belleville JP, et al. Effects of intravenous dexmedetomidine in humans, II: hemodynamic changes. Anesthesiology 1992; 77: 1134-1142.

[15] Hall JE, Uhrich TD, Barney JA, et al. Sedative, amnestic, and analgesic properties of small-dose dexmedetomidine infusions. Anesth Analg 2000; 90: 699-705.

[16] Taittonen MT, Aantaa R, Kirvela OA. Effect of clonidine on changes in plasma catecholamine concentrations and oxygen consumption caused by the cold pressor test. Br J Anaesth 1998; 81:140-144.

[17] Getrler R, Brown HC, Mitchell DH. Dexmedetomidine: a novel sedative-analgesic agent. Proc (Bayl Univ Med Cent) 2001; 14:1321.

[18] Fragen RJ, Fitzgerald PC. Effect of dexmedetomidine on the minimum alveolar concentration (MAC) of sevoflurane in adults age 55 to 70 years. J Clin Anesth 1999; 11: 466- 470. 
[19] Scheinin H, Jaakola ML, Sjovall S, et al. Intramuscular dexmedetomidine as premedication for general anaesthesia. A comparative multicenter study. Anesthesiology 1993; 78: 1065-1075.

[20] Jaakola ML, Ali-Melkkila T, Kanto J. Dexmedetomidine reduces intraocular pressure, intubation responses and anaesthetic requirements in patients undergoing ophthalmic surgery. $\mathrm{Br} \mathrm{J}$ Anaesth 1992; 68: 570-575.

[21] Peden CJ, Cloote AH, Stratford N, et al. The effect of intravenous dexmedetomidine premedication on the dose requirement of propofol to induce loss of consciousness in patients receiving alfentanil. Anaesthesia 2001; 6: 408-413.
Alfonsi P. Postanaesthetic shivering. Epidemiology, pathophysiology and approaches to prevention and management. Minerva Anestesiol 2003; 69: 438-442.

[23] Piper SN, Rohm KD, Suttner SW, et al. A comparison of nefopam and clonidine for the prevention of postanaesthetic shivering: a comparative, double-blind and placebo-controlled dose-ranging study. Anaesthesia 2004; 59: 559-564

[24] Stanski DR. Monitoring depth of anesthesia. In Miller RD, ed. Anesthesia, New York: Churchill Livingstone 1990; 1001-1029. 